\title{
Co-production of single cell oil and gluconic acid using oleaginous Cryptococcus podzolicus DSM 27192
}

Xiujuan Qian ${ }^{1}$, Olga Gorte ${ }^{3}$, Lin Chen ${ }^{1}$, Wenming Zhang ${ }^{1,2}$, Weiliang Dong ${ }^{1,2}$, Jiangfeng Ma ${ }^{1,2}$, Min Jiang ${ }^{1,2^{*}}$, Fengxue Xin ${ }^{1,2^{*}}$ and Katrin Ochsenreither ${ }^{3}$

\begin{abstract}
Background: The co-production of single cell oil (SCO) with value-added products could improve the economic viability of industrial SCO production. The newly isolated oleaginous yeast Cryptococcus podzolicus DSM 27192 was able to co-produce SCO intracellularly and gluconic acid (GA) extracellularly. In this study, the metabolic regulation of carbon distribution between SCO and GA through process optimization was comprehensively investigated.

Results: The carbon flow distribution between SCO and GA was significantly influenced by the cultivation conditions, such as nitrogen sources, glucose concentration and dissolved oxygen concentration. It was found that organic nitrogen sources were beneficial for SCO accumulation, while GA production was decreased. Dissolved oxygen concentration (DOC) was found to enhance SCO accumulation, while high glucose concentration was more favorable for GA accumulation. Hence, a two-stage DOC or glucose concentration-controlled strategy was designed to improve cell growth and direct carbon distribution between SCO and GA. Moreover, C. podzolicus DSM 27192 could degrade its stored lipids to synthesize GA in the late stationary phase, although considerable amounts of glucose remained unconsumed in the culture medium, indicating the importance of fermentation time control in co-production systems. All these observations provide opportunity to favor either the production of SCO or GA or rather their simultaneous production.
\end{abstract}

Conclusions: Co-production of SCO and GA by C. podzolicus DSM 27192 can improve the economical value for microbial lipid-derived biodiesel production. Moreover, the results of the proposed co-production strategy might give guidance for other co-production systems.

Keywords: Co-production, Single cell oil (SCO), Gluconic acid (GA), Regulation, Carbon flow

\section{Background}

Driven by the foreseeable depletion of crude oil and the highly controversial "food-or-fuel" discussion regarding plant-based biodiesel production, single cell oil (SCO) has been considered as an intriguing alternative for biodiesel production and oleochemical industries [1]. To unlock the economical competitiveness of SCO hindered

\footnotetext{
*Correspondence: bioengine@njtech.edu.cn; xinfengxue@njtech.edu.cn ${ }^{1}$ State Key Laboratory of Materials-Oriented Chemical Engineering, College of Biotechnology and Pharmaceutical Engineering, Nanjing Tech University, Puzhu South Road 30\#, Nanjing 211816, People's Republic of China

Full list of author information is available at the end of the article
}

by its relatively high production cost and low yield [2, 3], many efforts have been made on the utilization of lowcost feedstocks, optimization of fermentation conditions and genetic modification of lipid synthesis pathways in microbes [4-6]. However, the improvement is still limited, as the lipid yield and productivity are still too low [7-10]. Currently, the practical yield of SCO from glucose is only $\sim 0.22 \mathrm{~g}$ lipid/g glucose, since high amounts of carbon are used for the production of biomass and other metabolites [11].

The production of some metabolites is inevitable for the maintenance of metabolism; alternatively, an effective co-production system may be more beneficial than 
the repression or deletion of genes related to by-products synthesis, as it may prevent metabolic imbalances [12]. In addition, the co-production of the main metabolic products, e.g., SCO with value-added chemicals, may make full use of nutrients in the cultivation medium, improving the techno-economics of microbial lipid technology [13]. Successful precedents have been established for the coproduction of PHA with proteins, alcohols and biosurfactants [14]; $\beta$-galactosidase with ethanol [15]; erythritol with lipase [16]; lactic acid with chitin [17], etc. Currently, a number of co-production systems of SCO with other chemicals have also been reported, most of which have focused on the co-production with bioethanol [18], proteins [19] and some liposoluble products, such as carotenoid, fucoxanthin and pigments [20-22]. However, only little attention has been paid to the co-production of SCO with other bulk chemicals.

In our previous study, the oleaginous yeast Cryptococcus podzolicus DSM 27192 was isolated and identified. Preliminary fermentation results showed that it can accumulate high amounts of gluconic acid (GA) as a byproduct when growing on glucose [23]. $\mathrm{GA}\left(\mathrm{C}_{6} \mathrm{H}_{12} \mathrm{O}_{7}\right)$ is an oxidation product of glucose, which has been widely used in the food, medicine and cement industries for over 50 years $[24,25]$. Especially, the favorable effects of GA on human and animal health have boosted its use as a prebiotic in food production recently [26]. Due to its multiple applications in different aspects, the demand for GA has been steadily increasing globally. At present, the production of GA and its derivatives has been estimated to be approximately 60,000 ton/year, with production costs ranging from 1.20 to $8.50 \mathrm{US} \$ / \mathrm{kg}$, which restricts its application in many cases [27]. Hence, developing an effective and economically viable system for GA production is urgent.

In this study, the co-production of SCO and GA by using C. podzolicus DSM 27192 was investigated. The influence of nitrogen source, dissolved oxygen, glucose concentration as well as fermentation time on the production of SCO and GA was comprehensively analyzed. Furthermore, biochemical and technological considerations concerning the microbial behavior were assessed and critically discussed, which will provide more guidance for further lipid co-production strategies.

\section{Results and discussion}

According to literature, the production of GA and SCO is mainly influenced by three factors: (1) an excess of carbon; (2) nutrient limitation, e.g., nitrogen limitation; and (3) continuous aeration to ensure sufficient supply with oxygen. Therefore, these parameters were investigated accordingly $[11,24]$.

\section{Regulation of carbon flow between SCO and GA using different nitrogen sources}

It is known that cell growth and distribution of metabolites are strongly affected by nitrogen sources during microbial fermentation [28]. In a previous shake flask study, SCO accumulation in C. podzolicus DSM 27192 was found to be similar in both YM and mineral salt medium. Furthermore, $1.8 \mathrm{~g} / \mathrm{L}$ of GA was produced in mineral salt medium, while no GA was detected in YM medium (data not shown). A major difference between these two media was the nitrogen source. To further explore the effect of nitrogen sources on carbon flow distribution, different nitrogen sources including $\left(\mathrm{NH}_{4}\right)_{2} \mathrm{SO}_{4}$, YM-based nitrogen (peptone, yeast extract and malt extract) and yeast extract were investigated in bioreactor experiments to ensure optimal aeration and $\mathrm{pH}$ control. To be able to compare the influence of different nitrogen sources, the $\mathrm{C} / \mathrm{N}$ ratio was kept similar in all experiments as described by $\mathrm{Li}$ et al. [29] and Bellou et al. [30].

As shown in Fig. 1a, when $\left(\mathrm{NH}_{4}\right)_{2} \mathrm{SO}_{4}$ was used as the nitrogen source, $17.5 \mathrm{~g} / \mathrm{L}$ of GA was produced by C. podzolicus DSM 27192, while considerably lower GA concentrations of $4.8 \mathrm{~g} / \mathrm{L}, 4.6 \mathrm{~g} / \mathrm{L}$ and $6.0 \mathrm{~g} / \mathrm{L}$ were obtained in YM-based nitrogen, yeast extract medium and YM medium, respectively, suggesting a possible inhibition of organic nitrogen sources on GA production in contrast to inorganic ones. However, yeast extract is a complex mixture of nitrogenous compounds, carbon, sulfur, trace nutrients, vitamin B complex and other important growth factors. Thus, it is difficult to conclude which element(s) resulted in this phenomenon. In a previous study, some metals such as $\mathrm{Cu}^{2+}$ and $\mathrm{Fe}^{2+}$ in yeast extract have been reported to repress key enzyme activities, such as glucose oxidase (GO) in the GA production pathway [31-33]. However, the results are inconsistent with other studies, in which organic nitrogen sources, such as peptone and yeast extract, were found to have a stimulating effect on GO activity [34].

In terms of SCO production, organic nitrogen sources, such as yeast extract, were found to be favorable to improve the lipid content, since $49.9 \%$ and $39.6 \%$ were obtained in YM-based nitrogen and yeast extract medium, respectively. $40.1 \%$ was obtained by using YM medium, while a slightly lower lipid content of $36.3 \%$ was produced in $\left(\mathrm{NH}_{4}\right)_{2} \mathrm{SO}_{4}$ medium (Fig. 1b). However, when $\left(\mathrm{NH}_{4}\right)_{2} \mathrm{SO}_{4}$ was used as the nitrogen source, the highest biomass production $(40.6 \mathrm{~g} / \mathrm{L})$ was detected (Fig. 1c), while YM medium, YM-based nitrogen and yeast extract medium resulted in $22.4 \mathrm{~g} / \mathrm{L}, 18.6 \mathrm{~g} / \mathrm{L}$, and $24.3 \mathrm{~g} / \mathrm{L}$ of cell mass, respectively. These results imply that inorganic and organic nitrogen play different roles in biomass production and lipid accumulation 

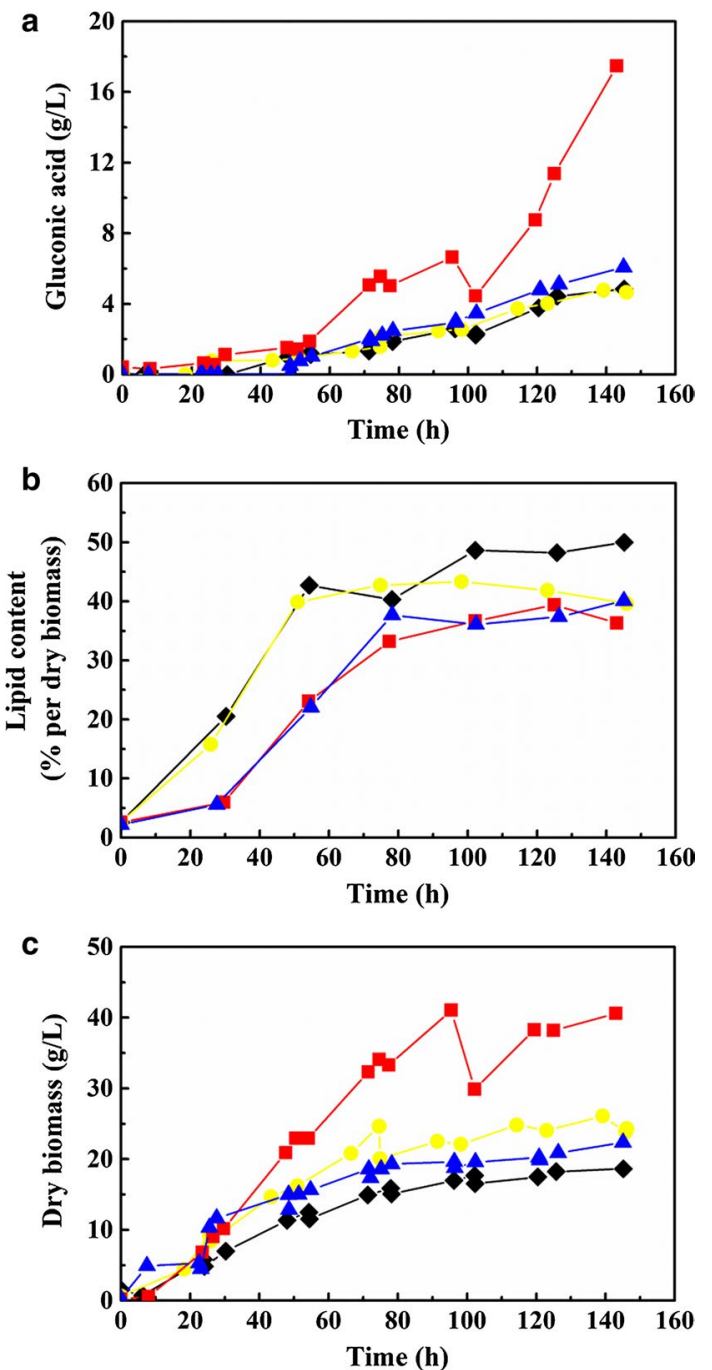

Fig. 1 Influence of different nitrogen sources on the production of SCO and GA. a GA production; b SCO accumulation; c cell growth. Red diamonds represent fermented C. podzolicus DSM 27192 in mineral salt medium with $\left(\mathrm{NH}_{4}\right)_{2} \mathrm{SO}_{4}$ as nitrogen source. Yellow dots and black rhombi represent C. podzolicus DSM 27192 grown in mineral salt medium with yeast extract and YM nitrogen as nitrogen source, respectively. The blue triangles show the properties of $C$. podzolicus DSM 27192 grown in YM medium. Experiments were done in a $2.5 \mathrm{~L}$ reactor, with $1.2 \mathrm{~L}$ of cultivation volume, $20^{\circ} \mathrm{C}, 600 \mathrm{rpm}$ agitation, and $1 \mathrm{vvm}$ gas aeration. The cultures were held for $\sim 150 \mathrm{~h}$

in the fermentation process, and that inorganic nitrogen sources are more beneficial for biomass accumulation, but less suitable for SCO production, while organic nitrogen sources improve lipid accumulation, but are less suitable for cell growth. These findings are consistent with the results reported by Bellou et al. [30]. Specifically, by measuring the enzyme activity of malic enzyme (ME) during Yarrowia lipolytica fermentation with different nitrogen sources, Bellou et al. found that ME may not be implicated in lipid biosynthesis in this yeast, and NADPH may be provided by the pentose phosphate pathway (PPP). The presence of organic nitrogen in low concentrations during lipogenesis was also required for NADPH supply of the lipogenic machinery in Y. lipolytica.

\section{Effect of glucose feeding on cell growth and carbon distribution}

Excess carbon source is a prerequisite for SCO accumulation, and high glucose concentrations also induce the expression of GO. Accordingly, different glucose concentrations ranging from 9 to $15 \%$ were adopted to investigate the effect of glucose dosage on SCO accumulation and GA production. As seen in Fig. 2, $21.7 \mathrm{~g} / \mathrm{L}$ of GA was produced when adding $15 \%$ glucose, with a yield of $0.16 \mathrm{~g} / \mathrm{g}$ from glucose, corresponding to an increase of $24 \%$ compared with $9 \%$ glucose addition. However, an increased GA production due to higher glucose concentration might also cause more hydrogen peroxide accumulation in the medium, resulting in a severe damage on cell growth [32]. As observed in our experiment, the biomass did decrease by $35.5 \%$ when the glucose concentration was increased from 9 to $15 \%$. In addition, cells generally tend to grow better at lower initial glucose concentration, since a high carbon source concentration might result in higher oxygen requirements during microbial cell growth, leading to a subsequent lower dissolved oxygen concentration (DOC) in the medium, which would force cells to enter the stationary growth phase prematurely [35].

With regard to the production of lipids, a content of $51.3 \%$ was obtained when the glucose concentration was increased from 9 to $15 \%$, leading to a $41.3 \%$ improvement (Fig. 2). However, an increase in lipid content does not necessarily mean an increased lipid production in total. Since SCO is accumulated intracellularly, lower biomass concentration does discount $\mathrm{SCO}$ yield. As observed in this study, only $13.4 \mathrm{~g} / \mathrm{L}$ of SCO was produced when $15 \%$ glucose was added, i.e., a 9\% decrease compared to SCO production with $9 \%$ glucose. In conclusion, a high glucose concentration is more favorable for lipid accumulation rather than SCO production.

As expected, fatty acid composition was not affected markedly by varying the glucose concentration. The major fatty acids of C. podzolicus DSM 27192 were still palmitic acid (C16:0, 20\%) and oleic acid (C18:1, 62\%) (Table 1). Exceptionally, linoleic acid (C18:2) content did increase by $14.3 \%$, from 7.7 to $8.8 \%$ in total lipids. A similar phenomenon was also reported for Y. lipolytica. When Y. lipolytica was cultivated with high initial glucose concentration, the concentration of cellular oleic acid decreased, while linoleic acid slightly increased [36]. This could be caused by an increased desaturation of 


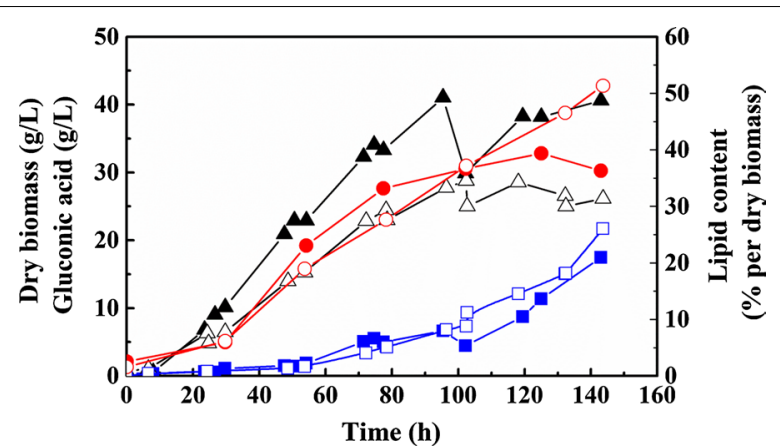

Fig. 2 Influence of high glucose feeding on cell growth and the co-production of SCO and GA. The solid symbols represent the control group of mineral salt medium fermentation, in which 50 $\mathrm{g} / \mathrm{L}$ of glucose was used as carbon source at the beginning, then up to $90 \mathrm{~g} / \mathrm{L}$ of glucose was fed every day. The hollow symbols represent the group of high glucose fermentation, in which $90 \mathrm{~g} / \mathrm{L}$ of glucose was used for cell growth at the beginning and then a fed-batch fermentation by feeding glucose up to $150 \mathrm{~g} / \mathrm{L}$ every day was carried out. Triangles represent cell growth, diamonds represent gluconic acid production, and dots represent SCO accumulation. The fermentation was also carried out in a $2.5 \mathrm{~L}$ bioreactor with $1.2 \mathrm{~L}$ fermentation volume, and the cultivation condition was similar to that done previously

oleic acid by $\Delta^{12}$ desaturase within the fatty acid elongation cycle [37]. Therefore, optimizing the initial glucose concentration might be an easy way to upgrade SCO value by enhancing the content of polyunsaturated fatty acids in C. podzolicus DSM 27192 and other oleaginous yeasts.

\section{Effect of DOC on cell growth and SCO-GA co-production}

Dissolved oxygen concentration reflects the real-time state of cell growth and glucose uptake under a given agitation and aeration rate. In the early phase of C. podzolicus DSM 27192 cultivation, the DOC decreased rapidly to zero and remained zero throughout the exponential phase, suggesting that oxygen supply was a limiting factor for cell growth and lipid production, which was also observed when using other yeasts [35, 38]. Likewise, oxygen pressure was also proven to play a key role in GA production [39]. Therefore, further research regarding DOC influence on the production of SCO and GA was conducted.

The growth curve of C. podzolicus DSM 27192 cultivated with DOC above $40 \%$ as well as the production of SCO and GA is illustrated in Fig. 3. After $40 \mathrm{~h}$ of cultivation, the agitation speed was increased gradually from $600 \mathrm{rpm}$ up to $930 \mathrm{rpm}$ to keep DOC above $40 \%$. The increased agitation resulted in a slight damage to cell growth, as $12 \%$ decrease in cell mass was found when compared with that under a constant agitation of $600 \mathrm{rpm}$. However, the negative influence of the increased agitation on GA production was more pronounced than on cell growth. GA production was maintained at a sluggish rate under high agitation condition, even after more glucose was supplemented. Only $9.6 \mathrm{~g} / \mathrm{L}$ of GA was obtained after $145 \mathrm{~h}$, with a GA yield of only $0.06 \mathrm{~g} / \mathrm{g}$ glucose (Table 2), showing a $45 \%$ decrease compared with that under a constant agitation of $600 \mathrm{rpm}$. The reason could be that the activity of GO dropped sharply due to the increase in agitation speed as reported by Petruccioli et al. [40].

In contrast, the increased DOC had a positive effect on SCO accumulation, as a noticeable increase from 36.3 to $47.8 \%$ in lipid content was observed, corresponding to an increased lipid yield of $0.11 \mathrm{~g} / \mathrm{g}$ glucose. This may be attributed to the upregulation of ATP-citrate lyase and malic enzyme at high DOC, which participate in lipid synthesis while the activity of $\mathrm{NAD}^{+}$-dependent isocitrate dehydrogenase was also found to decrease during the transition from low to high DOC in that study, usually a prerequisite for

Table 1 Fatty acid composition profile in \% of total fatty acids of C. podzolicus DSM 27192 growing in a defined media with different glucose concentrations

\begin{tabular}{|c|c|c|c|c|}
\hline Fatty acid species & $9 \%$ Glucose 600 rpm & $\begin{array}{l}15 \% \text { Glucose } \\
600 \mathrm{rpm}\end{array}$ & $9 \%$ Glucose $\mathrm{pO}_{2}>40 \%$ & $\begin{array}{l}15 \% \text { Glucose } \\
\mathrm{pO}_{2}>40 \%\end{array}$ \\
\hline Tetradecanoic acid (C 14:0) & 0.0 & 0.1 & 0.1 & 0.1 \\
\hline Palmitic acid (C 16:0) & 20.0 & 20.2 & 21.1 & 21.1 \\
\hline Octadecanoic acid (C 18:0) & 5.5 & 5.3 & 5.5 & 5.5 \\
\hline Oleic acid (C 18:1) & 62.9 & 61.9 & 61.5 & 61.5 \\
\hline Linoleic acid (C 18:2) & 7.7 & 8.8 & 8.1 & 8.1 \\
\hline Arachidic acid (C 20:0) & 0.7 & 0.8 & 0.8 & 0.8 \\
\hline Linolenic acid (C 18:3) & 2.2 & 1.9 & 1.8 & 1.8 \\
\hline Docosanoic acid (C 22:0) & 1.1 & 1.0 & 1.0 & 1.0 \\
\hline Erucic acid (C 22:1) & 0.0 & 0.0 & 0.0 & 0.0 \\
\hline Lignoceric acid (C 24:0) & 0.0 & 0.0 & 0.0 & 0.0 \\
\hline
\end{tabular}




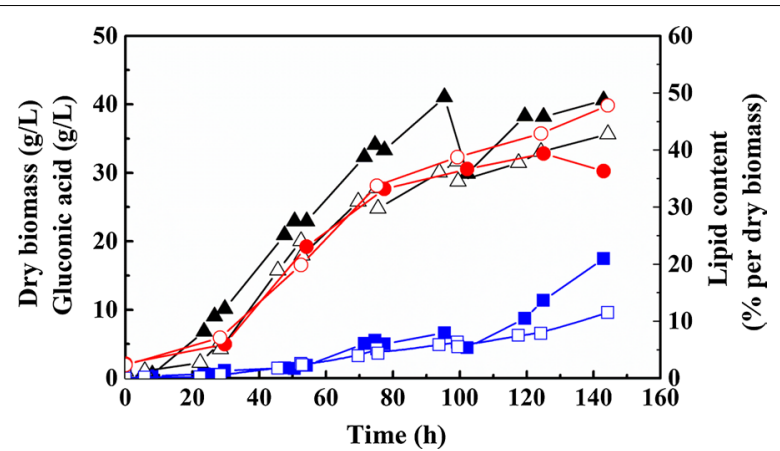

Fig. 3 Influence of high DOC on cell growth and co-production of SCO and GA. The solid symbols represent the control group growing in mineral salt medium with a constant agitation speed at $600 \mathrm{rpm}$. The hollow symbols represent a high DOC fermentation, when DOC was kept over $40 \%$ by increasing the agitation mechanically. Triangles represent cell growth, diamonds represent gluconic acid production, and dots represent $\mathrm{SCO}$ accumulation. Experiments were done in a $2.5 \mathrm{~L}$ reactor, with $1.2 \mathrm{~L}$ of cultivation volume, $20^{\circ} \mathrm{C}$ and $1 \mathrm{vvm}$ gas aeration, and the cultures were held for $\sim 150 \mathrm{~h}$

lipid accumulation [35]. Besides from Y. lipolytica and Rhodotorula glutinis, high DOC was beneficial for cell growth, but unfavorable for lipid accumulation in other studies $[41,42]$.

The changes of overall fatty acid composition under different DOC conditions were negligible (Table 1). For example, under constant agitation, the main fatty acids are palmitic acid (C16:0) 20.0\%, stearic acid (C18:0) 5.5\%, oleic acid (C18:1) 62.9\%, and linoleic acid (C18:2) 7.7\%. A nearly identical composition was obtained, when DOC was kept above 40\% (21.1\%, $5.5 \%, 61.5 \%$, and $8.1 \%$ of $\mathrm{C} 16: 0, \mathrm{C} 18: 0, \mathrm{C} 18: 1$ and C18:2, respectively). In contrast to Lipomyces starkeyi [8], an increased DOC did not decrease the saturation degree of fatty acids. Speculatively, the amount of oxygen required for the unsaturation is negligible when compared to cell propagation, energy metabolism, and total lipid biosynthesis in this yeast under current conditions.
SCO and GA accumulation under high DOC and high glucose feeding at different fermentation stages

Taken together, high DOC is favorable for SCO production, while high glucose concentration is favorable for GA production (Table 2). To explore the comprehensive effect of high DOC and high glucose addition on both cell growth and metabolites mainly SCO and GA production, experiments with high glucose feeding rate and high DOC above $40 \%$ were conducted. As expected, the growth of C. podzolicus DSM 27192 was severely inhibited by the increased glucose concentration and high agitation (Fig. 4). Only $21.8 \mathrm{~g} / \mathrm{L}$ of cell mass was obtained after $142 \mathrm{~h}$, resulting in the lowest lipid production of $11.7 \mathrm{~g} / \mathrm{L}$ (Table 2). In addition, the neutralization caused by the high DOC and high glucose addition resulted in only $15.4 \mathrm{~g} / \mathrm{L}$ of GA production.

It was found that cells grew fast during the growth phase, accumulating little SCO, with nearly no GA production. When the fermentation process entered the oleaginous phase after nitrogen depletion, glucose was channeled mainly to SCO accumulation, as relatively small amounts of GA were formed. At the end of the oleaginous phase, the cellular stored lipids were gradually degraded and presumably used for GA production, although glucose was still available in the medium (Fig. 4). By this strategy, it was possible to separate the production phases of both metabolites. Similar phenomena were also observed by using other oleaginous microorganisms. For example, when Aspergillus niger was cultivated on waste glycerol medium derived from the biodiesel industry, stored lipids were used to produce significant amounts of oxalic acid even under high glycerol concentration [43]. Also, stored lipids in Y. lipolytica were degraded and citric acid was produced despite high amounts of glycerol [44]. Generally, degradation of lipids for the production of other compounds occurs when carbon sources are completely exhausted $[45,46]$, or when the carbon source uptake rate cannot satisfy the anabolic activities inside the cell [44]. Especially during lipid accumulation, the uptake and metabolism of glucose are very

Table 2 Product titers and yields obtained at different fermentation parameters

\begin{tabular}{|c|c|c|c|c|c|c|c|c|}
\hline $\begin{array}{l}\text { Sugar } \\
\text { addition } \\
(\%)\end{array}$ & Dissolved $\mathrm{O}_{2}\left(\mathrm{pO}_{2}\right)$ & $\begin{array}{l}\text { Cell } \\
\text { density } \\
\text { (g/L) }\end{array}$ & $\begin{array}{l}\text { Lipid content } \\
\text { (\% per CDW) }\end{array}$ & $\begin{array}{l}\text { SCO } \\
\text { production } \\
\text { (g/L) }\end{array}$ & $\begin{array}{l}\text { GA } \\
\text { production } \\
\text { (g/L) }\end{array}$ & $\begin{array}{l}\text { Glucose } \\
\text { consumption } \\
\text { (g/L) }\end{array}$ & $\begin{array}{l}X_{L / g}(\mathrm{~g} \mathrm{SCO} / \mathrm{g} \\
\text { glucose) }\end{array}$ & $\begin{array}{l}X_{G / g}(\mathbf{g} \\
\mathrm{GA} / \mathrm{g} \\
\text { glucose })\end{array}$ \\
\hline 9 & 600 rpm & 40.6 & 36.3 & 14.7 & 17.5 & 156 & 0.09 & 0.11 \\
\hline 15 & 600 rpm & 26.2 & 51.3 & 13.4 & 21.7 & 140 & 0.10 & 0.16 \\
\hline 9 & $\mathrm{pO}_{2}>40 \%$ & 35.7 & 47.8 & 17.1 & 9.6 & 157 & 0.11 & 0.06 \\
\hline 15 & $\mathrm{pO}_{2}>40 \%$ & 21.8 & 53.8 & 11.7 & 15.4 & 122 & 0.10 & 0.13 \\
\hline
\end{tabular}

$X_{L / g}$ was estimated by the formula $X_{L / g}=S C O$ production/glucose consumption

$X_{G / g}$ was estimated by the formula $X_{L / g}=G A$ production/glucose consumption 


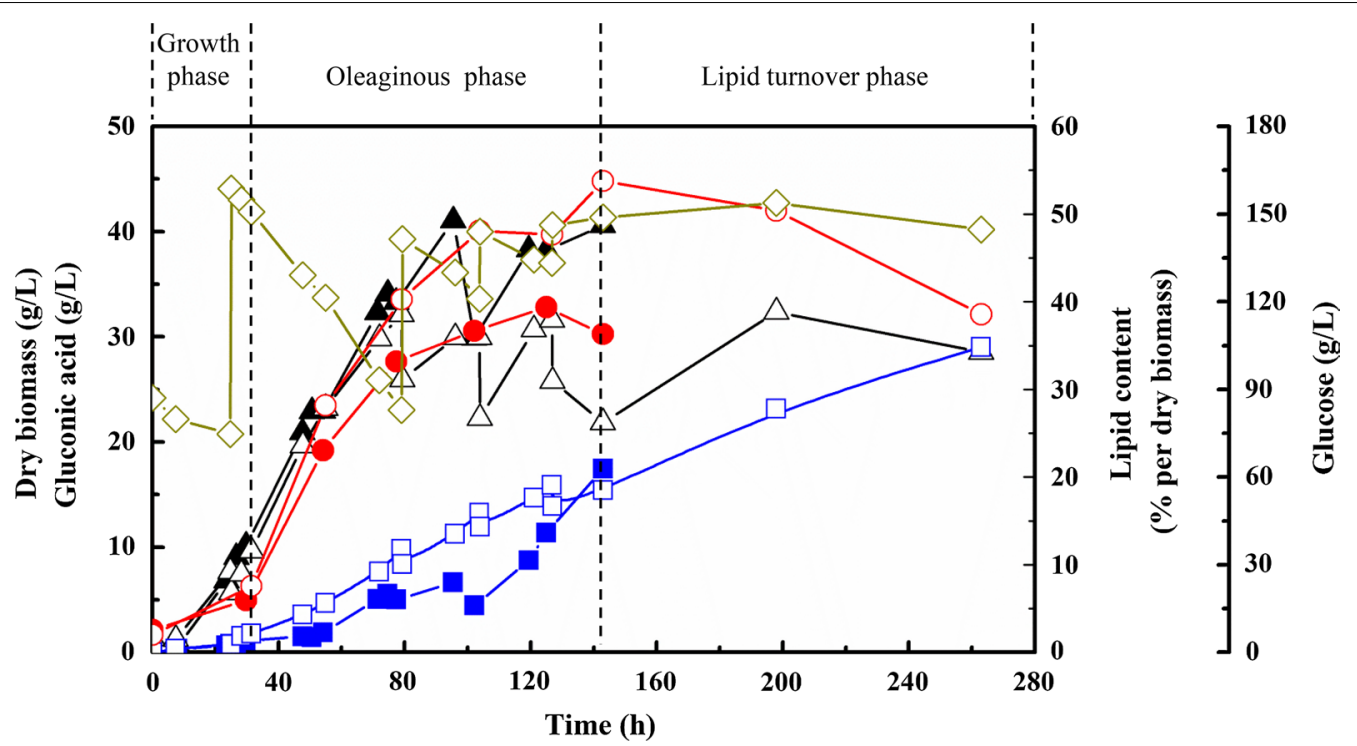

Fig. 4 Kinetics of dry cell mass, gluconic acid production and lipid accumulation and turnover in C. podzolicus DSM 27192. The solid symbols represent the control group similar to the previous two parts. The hollow symbols represent a high glucose concentration and DOC fermentation, for which $90 \mathrm{~g} / \mathrm{L}$ of glucose was used for cell growth at the beginning, then glucose was fed up to $150 \mathrm{~g} / \mathrm{L}$ every day, and DOC was kept over $40 \%$ by increasing the agitation mechanically. Triangles represent cell growth, diamonds represent gluconic acid production, dots represent SCO accumulation, and rhombi represent the glucose concentration. Experiments were done in a $2.5 \mathrm{~L}$ reactor, with $1.2 \mathrm{~L}$ of cultivation volume and $20^{\circ} \mathrm{C}$ and $1 \mathrm{vvm}$ gas aeration. The cell growth phase ended with the depletion of nitrogen in the growth medium. The oleaginous phase started after nitrogen depletion and ended after $140 \mathrm{~h}$ fermentation. Then, the lipid turnover phase took place

slow when nitrogen is depleted [47]. Thereby, nitrogen limitation would induce lipid accumulation in the first growth stage, while the GA biosynthesis pathway was not completely activated. Afterward, stored lipids were degraded to synthesize GA due to the restriction in glucose transportation and metabolism. However, further analysis of the metabolic balance between SCO and GA using transcriptomics or proteomics is needed for future studies.

\section{Conclusion}

Different factors influencing the carbon flow between SCO and GA production, namely nitrogen source, dissolved oxygen, glucose concentration and cultivation time, have been studied using C. podzolicus DSM 27192. The carbon distribution between SCO and GA was found susceptible to cultivation conditions. In detail, the GA production pathway was severely inhibited by organic nitrogen sources; high glucose addition greatly stimulated GA production, and both high glucose addition and high DOC were proven to promote SCO accumulation. However, either high glucose addition or high DOC had negative effects on cell mass growth, especially high glucose addition, which discounted the total SCO production. Hence, a two-stage DOC or glucose concentration control strategy was needed to improve cell growth and distribute carbon between SCO and GA. Moreover, the fermentation time is important for lipid production, since stored lipids will be degraded and used for the production of non-lipid metabolites in the late stationary phase. All these observations give the opportunity to favor either the production of SCO or GA or rather their simultaneous production. More importantly, this study might give more guidance for other co-production systems. Further studies should be focused on developing more efficient SCO co-production systems, improving the total product yield, amending the SCO production pathway, and enhancing specific high-value fatty acid production.

\section{Methods}

\section{Microorganisms and medium}

Cryptococcus podzolicus DSM 27192 used in this study was deposited at DSMZ culture collection in Braunschweig, Germany. The glycerol stocks were stored at $-80{ }^{\circ} \mathrm{C}$ in the in-house culture collection. Yeast colonies were maintained at $4{ }^{\circ} \mathrm{C}$ on Yeast Malt (YM) Agar plates $(\mathrm{g} / \mathrm{L})$ : yeast extract 3.0 , malt extract 3.0 , peptone 5.0 , glucose 10.0, agar 20.0, pH 6.2. For SCO production, a mineral salt medium was used as described by Ines Schulze et al. [23]. $50 \mathrm{~g} / \mathrm{L}$ of glucose was used initially, from the 2nd day the glucose was replenished to a maximum concentration of $90 \mathrm{~g} / \mathrm{L}$ after determining the actual concentration. 
The nitrogen content was around $8-12 \%$ in yeast extract, $10-13 \%$ in peptone, and $<1 \%$ in malt extract used in this study. In the experiment of nitrogen influence study, to keep the $\mathrm{C} / \mathrm{N}$ condition similar to the mineral salt medium, $12.1 \mathrm{~g} / \mathrm{L}$ of $\mathrm{YM}$ nitrogen $(3.3 \mathrm{~g} / \mathrm{L}$ of yeast extract, $5.5 \mathrm{~g} / \mathrm{L}$ of peptone, and $3.3 \mathrm{~g} / \mathrm{L}$ of malt extract) and $10 \mathrm{~g} / \mathrm{L}$ of yeast extract were used, respectively, to replace $\left(\mathrm{NH}_{4}\right)_{2} \mathrm{SO}_{4}$ as the nitrogen source.

\section{Batch fermentation in bioreactor}

A loopful of cells from YM agar plates was used to inoculate $20 \mathrm{~mL}$ of mineral salt medium $(50 \mathrm{~g} / \mathrm{L}$ of glucose as the carbon source) in a baffled shake flask and incubated in a gyratory shaker at $20{ }^{\circ} \mathrm{C}$ and $130 \mathrm{rpm}$ for approximately $24 \mathrm{~h}$. A second pre-culture was carried out using the same conditions. The second pre-culture was prepared from the first pre-culture in $200 \mathrm{~mL}$ culture medium in $2 \mathrm{~L}$ shake flasks with an initial $\mathrm{OD}_{600}$ of 1.0.

Fermentation was performed in a $2.5 \mathrm{~L}$ fermenter (Infors HT, Bottmingen, Switzerland; Minifors fermenter) with working volume of $1.2 \mathrm{~L}$, an initial $\mathrm{OD}_{600}$ of $0.5-1.0$ at $600 \mathrm{rpm}$, and $1 \mathrm{vvm}$ aeration rate without control of dissolved oxygen level $\left(\mathrm{pO}_{2}\right)$. The $\mathrm{pO}_{2}$ value was measured constantly by a probe. The control of $\mathrm{pH}$ to 6.0 was done automatically by the addition of $4 \mathrm{M}$ $\mathrm{H}_{3} \mathrm{PO}_{4}$ and $4 \mathrm{M} \mathrm{NaOH}$. In each fermenter, Contraspum A 4050 HAC (Zschimmerund Schwarz GmbH und Co KG, Lahnstein, Germany) was applied as antifoam agent. Each day, $20 \mathrm{~mL}$ of salt solution and $20 \mathrm{~mL}$ of trace element solution were fed into the medium.

All experiments were done in independent duplicates under the same condition.

\section{Determination of cell mass}

The cell concentration in the culture medium was determined by the optical density at $600 \mathrm{~nm}\left(\mathrm{OD}_{600}\right)$ with the initial culture medium as blank. All samples were diluted to an optical density of $0.2-0.8$ at $600 \mathrm{~nm}$ for measurement.

Cell dry biomass (CDW) was analyzed gravimetrically. $1 \mathrm{~mL}$ aliquot of the culture broth was transferred into a pre-dried and pre-weighed $1.5 \mathrm{~mL}$ reaction tube and centrifuged at 13,000 rpm for $5 \mathrm{~min}$. The supernatant was collected and used for the determination of glucose, GA, and acetic acid. The cell pellet was washed with $1 \mathrm{~mL}$ saline $(0.9 \% \mathrm{NaCl})$, dried at $60^{\circ} \mathrm{C}$ for $24 \mathrm{~h}$ and weighed. For each sample, all parameters were measured in duplicate.

\section{Determination of glucose and GA}

For glucose determination, $45 \mu \mathrm{L} 4 \mathrm{M} \mathrm{NH}_{3} \mathrm{Cl}$ and $100 \mu \mathrm{L}$ $1.2 \mathrm{M} \mathrm{MgSO}_{4}$ were added to $1 \mathrm{~mL}$ pure supernatant and subsequently centrifuged for $5 \mathrm{~min}$ at $20,000 \times g$ after
5 min of incubation. $500 \mu \mathrm{L}$ supernatant was then transferred to $500 \mu \mathrm{L} 0.1 \mathrm{M} \mathrm{H}_{2} \mathrm{SO}_{4}$, mixed, and incubated for $15 \mathrm{~min}$. After the final centrifugation step of $15 \mathrm{~min}$ at $20,000 \times g$, the supernatant was used for HPLC analysis. The analysis was performed with a standard HPLC device (Agilent 1100 Series, Agilent, Germany) with a Rezex ROA organic acid $\mathrm{H}^{+}(8 \%)$ column (300 by $7.8 \mathrm{~mm}, 8 \mathrm{~m}$; Phenomenex) protected by a Rezex ROA organic acid $\mathrm{H}^{+}(8 \%)$ guard column (50 by $7.8 \mathrm{~mm}$ ). Separation was performed under isocratic conditions at $50{ }^{\circ} \mathrm{C}$ (column temperature) for $45 \mathrm{~min}$ with $5 \mathrm{mM} \mathrm{H}_{2} \mathrm{SO}_{4}$ as the mobile phase at a constant flow rate of $0.4 \mathrm{~mL} / \mathrm{min}$. Detection of carbohydrate was achieved via an Agilent 1200 series refractive index detector at $50{ }^{\circ} \mathrm{C}$.

For GA analysis, the untreated supernatant was collected and diluted to an appropriate concentration using $20 \mathrm{mM} \mathrm{KH} \mathrm{PO}_{4}(\mathrm{pH} \mathrm{2.5)}$. The analysis was performed with a standard HPLC device (Agilent1100 Series, Agilent Technologies Deutschland $\mathrm{GmbH}$, Böblingen, Germany) equipped with a $150 \times 4.6 \mathrm{~mm}$ HPLC column Synergi $^{\mathrm{TM}} 4 \mu \mathrm{m}$ Fusion-RP $80 \AA$ (Phenomenex, Aschaffenburg, Germany; $00 \mathrm{~F}-4424-\mathrm{E} 0)$ at $30{ }^{\circ} \mathrm{C}$ column temperature. $20 \mathrm{mM} \mathrm{KH}_{2} \mathrm{PO}_{4}(\mathrm{pH} 2.5)(\mathrm{A})$ and $100 \%$ methanol (B) were used as eluents to drive the following temporal gradient: 0-0.5 min 100\% eluent A, 0.5-10 min increase of eluent B from 0 to $10 \%, 10-12$ min decrease of eluent $B$ from $10 \%$ back to $0 \%$ and $12-14$ min again $100 \%$ eluent A. $10 \mu \mathrm{L}$ sample was injected, a flow rate of $1 \mathrm{~mL} / \mathrm{min}$ was adjusted, and peaks were detected via UV at $220 \mathrm{~nm}$.

\section{Lipid extraction and determination of fatty acid methyl esters}

$20 \mathrm{~mL}$ aliquot of the culture broth was centrifuged (4700 rpm, $5 \mathrm{~min}$ ), the pellet was resuspended in saline $(0.9 \% \mathrm{NaCl})$. and centrifuged (4700 rpm, $5 \mathrm{~min})$ again. The supernatant was discarded and the pellet was freeze dried $\left(-30{ }^{\circ} \mathrm{C}, 0.370 \mathrm{mbar}\right)$. Sample preparation for the quantitative and qualitative gas chromatographic analysis was done in a one-step-procedure of direct esterification coupled with extraction. A portion $(20 \mathrm{mg})$ of freeze-dried biomass was weighed into a $15 \mathrm{~mL}$ glass Falcon with Teflon cap. $1.5 \mathrm{~mL}$ of hexane and $0.5 \mathrm{~mL}$ of $2.0 \mathrm{mg} / \mathrm{mL}$ internal standard (methyl benzoate dissolved in hexane) were added as solvent for lipid extraction. In addition, $2 \mathrm{~mL} \mathrm{15 \%}$ $\mathrm{H}_{2} \mathrm{SO}_{4}$ in methanol was added for esterification. Then, the sample was heated up to $100{ }^{\circ} \mathrm{C}$ for $2 \mathrm{~h}$ with continuous shaking. After cooling on ice, $1 \mathrm{~mL}$ demineralized water was added, and the mixture was centrifuged for 5 min with $2500 \mathrm{rpm}$ at $4{ }^{\circ} \mathrm{C}$. Afterward, $1 \mu \mathrm{L}$ of the upper phase was analyzed via chromatography (Agilent Technologies, $6890 \mathrm{~N}$ Network GC-System). The instrument was equipped with a DBWax column (Length: $30 \mathrm{~m}$, diam: $0.25 \mathrm{~mm}$, film: $0.25 \mu \mathrm{m}$; Agilent Technologies Deutschland 
GmbH, Böblingen, Germany; 122-7032) and a flame ionization detector and worked with a pressure of 1.083 bar and initial temperature of $40{ }^{\circ} \mathrm{C}$. The column temperature was increased from 40 to $250{ }^{\circ} \mathrm{C}$ at a rate of $8{ }^{\circ} \mathrm{C} / \mathrm{min}$. The temperature was held at $250{ }^{\circ} \mathrm{C}$ for $10 \mathrm{~min}$ before cooling down to $40^{\circ} \mathrm{C}$. The total fatty acid content and the identification of fatty acids were obtained using the standard RM3 FAME Mix (Sigma Aldrich, Taufkirchen, Germany; 072561AMP) and Marine FAME Mix (Acid Methyl Ester Marine Oil FAME Mix) (Restek GmbH, Bad Homburg, Germany; 35066). Fatty acids which represented less than $1 \%$ of total fatty acids were combined to "trace fatty acids".

\section{Abbreviations}

SCO: single cell oil; GA: gluconic acid; GO: glucose oxidase; DOC: dissolved oxygen concentration.

\section{Acknowledgements}

Not applicable.

\begin{abstract}
Authors' contributions
XJQ conceived and designed the experiments, performed the laboratory work, analyzed and interpreted the data, and drafted the paper. OG and LC performed the sample determination. WMZ, WLD, and JFM analyzed the metabolic pathway and enzyme function, and critically revised the manuscript. MJ, FXX, and KO contributed to the experimental design and data interpretation and also critically revised the manuscript. All authors read and approved the final manuscript.
\end{abstract}

\section{Funding}

This work was supported by the National Natural Science Foundation of China (No. 21706125, No. 21706124) and the Jiangsu Province Natural Science Foundation for Youths (BK20170993).

\section{Availability of data and materials}

The information about accession numbers is given in the manuscript.

\section{Ethics approval and consent to participate}

Not applicable.

\section{Consent for publication}

All authors consent to the publication of the manuscript in Biotechnology for Biofuels.

\section{Competing interests}

The authors declare that they have no competing interests.

\begin{abstract}
Author details
${ }^{1}$ State Key Laboratory of Materials-Oriented Chemical Engineering, College of Biotechnology and Pharmaceutical Engineering, Nanjing Tech University, Puzhu South Road 30\#, Nanjing 211816, People's Republic of China. ${ }^{2}$ Jiangsu National Synergetic Innovation Center for Advanced Materials (SICAM), Nanjing Tech University, Nanjing 211816, People's Republic of China. ${ }^{3}$ Institute of Process Engineering in Life Sciences, Section II: Technical Biology, Karlsruhe Institute of Technology, Fritz-Haber-Weg 4, 76131 Karlsruhe, Germany.
\end{abstract}

Received: 30 January 2019 Accepted: 15 May 2019

Published online: 21 May 2019

\section{References}

1. Huang C, Chen XF, Xiong L, Chen XD, Ma LL, Chen Y. Single cell oil production from low-cost substrates: the possibility and potential of its industrialization. Biotechnol Adv. 2013;31:129-39.
2. Qin L, Liu L, Zeng AP, Wei D. From low-cost substrates to single cell oils synthesized by oleaginous yeasts. Bioresour Technol. 2017;245:1507-19.

3. Carsanba E, Papanikolaou S, Erten H. Production of oils and fats by oleaginous microorganisms with an emphasis given to the potential of the nonconventional yeast Yarrowia lipolytica. Crit Rev Biotechnol. 2018;38:1230-43.

4. Ochsenreither K, Glück C, Stressler T, Fischer L, Syldatk C. Production strategies and applications of microbial single cell oils. Front Microbiol. 2016;7:1539.

5. Muniraj IK, Uthandi SK, Hu ZH, Xiao LW, Zhan XM. Microbial lipid production from renewable and waste materials for second-generation biodiesel feedstock. Environ Technol Rev. 2015:4:1-16.

6. Qiao KJ, Abidi SHI, Liu HJ, Zhang HR, Chakraborty S, Watson N, et al. Engineering lipid overproduction in the oleaginous yeast Yarrowia lipolytica. Metab Eng. 2015;29:56-65.

7. Poontawee R, Yongmanitchai W, Limtong S. Efficient oleaginous yeasts for lipid production from lignocellulosic sugars and effects of lignocellulose degradation compounds on growth and lipid production. Process Biochem. 2017:53:44-60.

8. Calvey $\mathrm{CH}$, Su Y-K, Willis LB, McGee M, Jeffries TW. Nitrogen limitation, oxygen limitation, and lipid accumulation in Lipomyces starkeyi. Bioresour Technol. 2016;200:780-8.

9. Friedlander J, Tsakraklides V, Kamineni A, Greenhagen EH, Consiglio AL, MacEwen K, et al. Engineering of a high lipid producing Yarrowia lipolytica strain. Biotechnol Biofuels. 2016:9:77.

10. Fei Q, Wewetzer SJ, Kurosawa K, Rha C, Sinskey AJ. High-cell-density cultivation of an engineered Rhodococcus opacus strain for lipid production via co-fermentation of glucose and xylose. Process Biochem. 2015;50:500-6.

11. Jin MJ, Slininger PJ, Dien BS, Waghmode S, Moser BR, Orjuela A, et al. Microbial lipid-based lignocellulosic biorefinery: feasibility and challenges. Trends Biotechnol. 2015;33:43-54.

12. Liang QF, Qi QS. From a co-production design to an integrated single-cell biorefinery. Biotechnol Adv. 2014;32:1328-35.

13. Zhang $C L$, Shen HW, Zhang XB, Yu X, Wang H, Xiao S, et al. Combined mutagenesis of Rhodosporidium toruloides for improved production of carotenoids and lipids. Biotechnol Lett. 2016;38:1733-8.

14. LiT, Elhadi D, Chen GQ. Co-production of microbial polyhydroxyalkanoates with other chemicals. Metab Eng. 2017;43:29-36.

15. You SP, Zhang JY, Yin QD, Wei Q, Su RX, He ZM. Development of a novel integrated process for co-production of $\beta$-galactosidase and ethanol using lactose as substrate. Bioresour Technol. 2017;230:15-23.

16. Liu XY, Yu XJ, Lv JS, Xu JX, Xia J, Wu Z, et al. A cost-effective process for the coproduction of erythritol and lipase with Yarrowia lipolytica M53 from waste cooking oil. Food Bioprod Process. 2017;103:86-94.

17. Liu Y, Liao W, Chen S. Co-production of lactic acid and chitin using a pelletized filamentous fungus Rhizopus oryzae cultured on cull potatoes and glucose. J Appl Microbiol. 2010;105:1521-8.

18. Kim I, Seo YH, Kim GY, Han Jl. Co-production of bioethanol and biodiesel from corn stover pretreated with nitric acid. Fuel. 2015;143:285-9.

19. Halim R, Webley PA, Martin GJO. The CIDES process: fractionation of concentrated microalgal paste for co-production of biofuel, nutraceuticals, and high-grade protein feed. Algal Res. 2016;19:299-306.

20. Saenge C, Cheirsilp B, Suksaroge TT, Bourtoom T. Potential use of oleaginous red yeast Rhodotorula glutinis for the bioconversion of crude glycerol from biodiesel plant to lipids and carotenoids. Process Biochem. 2011;46:210-8

21. Gao BY, Chen AL, Zhang WY, Li AF, Zhang CW. Co-production of lipids, eicosapentaenoic acid, fucoxanthin, and chrysolaminarin by Phaeodactylum tricornutum cultured in a flat-plate photobioreactor under varying nitrogen conditions. J Ocean Univ China. 2017;16:916-24.

22. Bai MD, Cheng $\mathrm{CH}$, Wan HM, Lin YH. Microalgal pigments potential as byproducts in lipid production. J Taiwan Inst Chem Eng. 2011;42:783-6.

23. Schulze I, Hansen S, Großhans S, Rudszuck T, Ochsenreither K, Syldatk C, et al. Characterization of newly isolated oleaginous yeasts-Cryptococcus podzolicus, Trichosporon porosum and Pichia segobiensis. AMB Express. 2014:4:24.

24. Ramachandran S, Fontanille P, Pandey A, Larroche C. Gluconic acid: properties, applications and microbial production. Food Technol Biotechnol. 2006:44:185-95. 
25. Qi PY, Chen SS, Chen J, Zheng JW, Zheng XL, Yuan YZ. Catalysis and reactivation of ordered mesoporous carbon-supported gold nanoparticles for the base-free oxidation of glucose to gluconic acid. ACS Catal. 2015;5:2659-70.

26. Cañete-Rodríguez AM, Santos-Dueñas IM, Jiménez-Hornero JE, Ehrenreich A, Liebl W, García-García I. Gluconic acid: properties, production methods and applications - an excellent opportunity for agro-industrial byproducts and waste bio-valorization. Process Biochem. 2016;51:1891-903.

27. Pal P, Kumar R, Banerjee S. Manufacture of gluconic acid: a review towards process intensification for green production. Chem Eng Process. 2016;104:160-71.

28. da Cruz SH, Batistote M, Ernandes JR. Effect of sugar catabolite repression in correlation with the complexity of the nitrogen source on yeast growth and fermentation. J Struct Inst Brew. 2015;109:349-55.

29. Li Y, Chen J, Liang D-F, Lun S-Y. Effect of nitrogen source and nitrogen concentration on the production of pyruvate by Torulopsis glabrata. J Biotechnol. 2000;81:27-34.

30. Bellou S, Triantaphyllidou I-E, Mizerakis P, Aggelis G. High lipid accumulation in Yarrowia lipolytica cultivated under double limitation of nitrogen and magnesium. J Biotechnol. 2016;234:116-26.

31. Dubey MK, Zehra A, Aamir M, Meena M, Ahirwal L, Singh S, et al. Improvement strategies, cost effective production, and potential applications of fungal glucose oxidase (GOD): current updates. Front Microbiol. 2017:8:1032.

32. Wong CM, Wong KH, Chen XD. Glucose oxidase: natural occurrence, function, properties and industrial applications. Appl Microbiol Biotechnol. 2008;78:927-38.

33. Gunny AAN, Arbain D, Ahmad MS, Tompang MF. Screening of medium components for glucose oxidase production by Aspergillus terreus UniMAP AA-1. In: International conference on food engineering and biotechnology, IPCBEE, IACSIT press, Singapore. vol. 9. 2011. p. 73-6.

34. Bankar SB, Bule MV, Singhal RS, Ananthanarayan L. Optimization of Aspergillus niger fermentation for the production of glucose oxidase. Food Bioprocess Technol. 2009;2:344-52.

35. Bellou S, Makri A, Triantaphyllidou I-E, Papanikolaou S, Aggelis G. Morphological and metabolic shifts of Yarrowia lipolytica induced by alteration of the dissolved oxygen concentration in the growth environment. Microbiology. 2014;160:807-17.

36. Papanikolaou S, Chatzifragkou A, Fakas S, Galiotou-Panayotou M, Komaitis M, Nicaud JM, et al. Biosynthesis of lipids and organic acids by Yarrowia lipolytica strains cultivated on glucose. Eur J Lipid Sci Technol. 2009;111:1221-32.
37. Lee J-E, Vadlani PV, Min D. Sustainable production of microbial lipids from lignocellulosic biomass using oleaginous yeast cultures. J Sustain Bioenergy Syst. 2017;7:36-50.

38. Galafassi S, Cucchetti D, Pizza F, Franzosi G, Bianchi D, Compagno C. Lipid production for second generation biodiesel by the oleaginous yeast Rhodotorula graminis. Bioresour Technol. 2012;111:398-403.

39. Tan XS, Deng WP, Liu M, Zhang QH, Wang Y. Carbon nanotube-supported gold nanoparticles as efficient catalysts for selective oxidation of cellobiose into gluconic acid in aqueous medium. Chem Commun. 2009;41:7179-81.

40. Petruccioli M, Fenice M, Piccioni P, Federici F. Effect of stirrer speed and buffering agents on the production of glucose oxidase and catalase by Penicillium variabile (P16) in benchtop bioreactor. Enzyme Microb Technol. 1995;17:336-9.

41. Papanikolaou S, Chevalot I, Komaitis M, Marc I, Aggelis G. Single cell oil production by Yarrowia lipolytica growing on an industrial derivative of animal fat in batch cultures. Appl Microbiol Biotechnol. 2002;58:308-12.

42. Yen HW, Zhang ZY. Effects of dissolved oxygen level on cell growth and total lipid accumulation in the cultivation of Rhodotorula glutinis. J Biosci Bioeng. 2011;112:71-4.

43. André A, Diamantopoulou P, Philippoussis A, Sarris D, Komaitis M, Papanikolaou S. Biotechnological conversions of bio-diesel derived waste glycerol into added-value compounds by higher fungi: production of biomass, single cell oil and oxalic acid. Ind Crops Prod. 2010;31:407-16.

44. Makri A, Fakas S, Aggelis G. Metabolic activities of biotechnological interest in Yarrowia lipolytica grown on glycerol in repeated batch cultures. Bioresour Technol. 2010;101:2351-8.

45. Papanikolaou S, Aggelis G. Lipids of oleaginous yeasts. Part I: biochemistry of single cell oil production. Eur J Lipid Sci Technol. 2011;113:1031-51.

46. Dourou M, Aggeli D, Papanikolaou S, Aggelis G. Critical steps in carbon metabolism affecting lipid accumulation and their regulation in oleaginous microorganisms. Appl Microbiol Biotechnol. 2018;102:2509-23.

47. Palma M, Madeira SC, Mendes-Ferreira A, Sá-Correia I. Impact of assimilable nitrogen availability in glucose uptake kinetics in Saccharomyces cerevisiae during alcoholic fermentation. Microb Cell Fact. 2012;11:99.

\section{Publisher's Note}

Springer Nature remains neutral with regard to jurisdictional claims in published maps and institutional affiliations.
Ready to submit your research? Choose BMC and benefit from:

- fast, convenient online submission

- thorough peer review by experienced researchers in your field

- rapid publication on acceptance

- support for research data, including large and complex data types

- gold Open Access which fosters wider collaboration and increased citations

- maximum visibility for your research: over 100M website views per year

At BMC, research is always in progress.

Learn more biomedcentral.com/submissions 